\title{
Resumption of laser/IPL skin services post COVID-19 lockdown-British Medical Laser Association (BMLA) guidance document
}

\author{
Vishal Madan ${ }^{1,2}$ \\ Received: 28 May 2020 / Accepted: 22 June 2020 / Published online: 27 June 2020 \\ (C) Springer-Verlag London Ltd., part of Springer Nature 2020
}

\begin{abstract}
The COVID-19 pandemic has had a significant negative impact on the global health economies. As health care resources have been prioritised to cater for patients affected by COVID-19, routine health care services have remained suspended. In an effort to slow the spread of SARS-CoV-2 virus, the UK introduced a country-wide lockdown which came into effect on the 23 rd March 2020. Since then, clinics offering laser and intense pulsed light services have remained closed for business. As the rate of COVID-19 infection slows, the UK government has issued guidance for lifting of the lockdown in a cautious and phased manner. With this in view and to facilitate safe resumption of laser and intense pulsed light services, the British Medical Laser Services has issued this guidance document, based on best available and current scientific evidence.
\end{abstract}

Keywords Aerosol · Coronavirus · COVID $19 \cdot$ Guidance $\cdot$ Laser · Pandemic $\cdot$ Plume $\cdot$ SARS-CoV-2 virus

\section{Introduction}

As strategies to relax the COVID-19 lockdown that commenced in the UK on the 23rd March 2020 are being discussed and implemented, many laser practitioners will seek to resume their services after a period of 10-12 weeks.

This document specifically addresses challenges laser practitioners and clinic managers face while reopening their clinics to offer laser and IPL services, taking into account that the reproduction rate ' $\mathrm{R} 0$ number' for transmission of COVID-19 is $0.7-1$ at the time of issuance of this guidance ${ }^{1}$.

Several clinics offer a complement of aesthetic treatments of which lasers and IPL form a component. As this document specifically addresses the challenges in resumption of laser/ IPL skin services, the reader should refer to general guidance/

Consortium (BMLA) ${ }^{2}$ Jon Exley, Honorary Secretary; ${ }^{2}$ Vasant Oswal, Honorary Vice-President; ${ }^{2}$ Harry Moseley, Emeritus Professor and Past President; ${ }^{2}$ Reem Hana, Executive Committee Member; ${ }^{2}$ Tom Lister, Executive Committee Member; Vishal Madan, President

Vishal Madan

vishal.madan@srft.nhs.uk

1 Salford Royal NHS Foundation Trust, Stott Lane, Salford M6 8HD, UK

2 British Medical Laser Association, Manchester, UK publications issued by other organisations such as the Joint council for cosmetic practitioners on commencing non-laser treatments and non-dermatological laser/IPL services (https:// www.jccp.org.uk/NewsEvent/covid-19-preparing-for-returnto-work $)^{2}$.

\section{Pre-treatment screening}

Proper pre-treatment screening should substantially reduce the risk of contact with symptomatic patient displaying the commonest signs and symptoms of COVID-19 infection such as high temperature, new and persistent cough, loss or change to sense of smell or taste ${ }^{3}$. Until such time that antibody testing becomes routinely available, all patients attending for laser treatments should be presumed COVID-19 positive.

Excluded from this document are precursory checks and screening of potential patients for signs of COVID-19, general and COVID-19-specific hygiene in clinic reception etc. which are covered in detail elsewhere (https://www.jccp.org.uk/ NewsEvent/covid-19-preparing-for-return-to-work) ${ }^{2}$.

\section{Guidance}

1. Risk assessment: lasers, aerosols and COVID 
2. Risk management
A. General hygiene
B. PPE
C. Ventilation
D. Smoke evacuation systems
E. Laser equipment

\section{Risk assessment: lasers, aerosols and COVID}

Aerosols are particles of respirable size generated by both human and environmental sources and that can remain viable and airborne for extended periods in indoor air ${ }^{4}$.

The SARS-CoV-2 virus which is the causative agent of COVID-19 pandemic is thought to spread mainly from person-to-person through respiratory droplets produced when an infected person breathes, coughs, sneezes or talks. Infection with SARS-CoV-2 occurs primarily by inhalation of aerosolised virus or secondarily by contact with droplets and contaminated fomites such as garments, instruments and furniture.

SARS-CoV-2 virus has a size of 0.06-0.14 $\mu \mathrm{m}$ with mean size of $0.1 \mu^{5}$. During a sneeze or a cough or while talking, "droplet sprays" of virus laden respiratory tract fluid, typically greater than $5 \mu \mathrm{m}$ in diameter, impact directly on a susceptible individual. Alternatively, a susceptible person can inhale microscopic aerosol particles (droplet nuclei) consisting of the residual solid components of evaporated respiratory droplets, which are tiny enough $(<5 \mu \mathrm{m})$ to remain airborne for hours, particularly in enclosed spaces with poor or no ventilation ${ }^{4}$.

Lasers and intense pulsed light (IPL) treatment of tissues generates plumes and aerosols which include both combustion and non-combustion-generated products including tissue(s), gases, particulate materials, steam and carbonised material (smoke). All ablative and non-ablative laser procedures can generate potentially hazardous plumes.

In a recent study, gas chromatography-mass spectrometry of plume during laser hair removal showed presence of 377 chemical compounds comprising suspected carcinogens and environmental toxins ${ }^{6}$. Ablative laser-generated plume has been shown to contain intact human papillomavirus DNA, viable bacteriophages and viable human immunodeficiency virus ${ }^{7}$. Similarly, micron-sized tattoo ink particles potentially contaminated with aerosolised blood products have been detected following laser tattoo removal ${ }^{8}$.

Results of polymerase chain reaction (PCR) and viral RNA testing for SARS-CoV-2 from blood samples of most patients with COVID-19 infection have been negative and viraemia is very uncommon ${ }^{9}$. This is an important finding which should reassure practitioners that the risk of viable SARS-CoV-2 in aerosol generated from laser treatments of asymptomatic COVID-19 patients should be very low. As of date, no studies looking at SARS-CoV-2 viral RNA on intact skin or hair follicles or the effect of laser treatments on viral particles have been published. For this reason, all laser treatments should be considered potentially COVID-19 aerosol-generating procedures (AGP) and all necessary precautions should be followed.

Based on the above, and until such time that evidence to the contrary is available, one could assume that the main route of COVID-19 infection in laser/IPL procedures remains patientgenerated respiratory aerosol but still considers lasergenerated plume/aerosol as potentially infective.

\section{Risk management}

General hygiene and enhanced infection control procedures In any setting, hand hygiene remains the most important defence against spread of COVID-19. Practitioners should also focus on surface decontamination procedures. These form the basis of reduction of virus transmission. Guidance regarding this is freely available ${ }^{2,3}$.

PPE_-personal protection equipment comprises face masks, gloves, gowns/aprons, face shields and caps Barrier precautions such as masks and respirators are regarded as the last line of defence against viral transmission secondary to hand washing and other hygiene measures. In the case of laser/IPL treatments, proper eye protection is imperative and should not be ignored. Resources detailing correct methods of donning and doffing of PPE are freely available ${ }^{10}$.

\section{Face masks and respirators}

Face masks protect against aerosol spread from inside out. They are tested in the direction of expiration (from inside to outside). They offer minimal protection to the wearer from inhalation of droplets. Face masks can simply be classified as surgical and non-surgical. Surgical masks worn by the practitioner protect the patient and the environment (air, surfaces, equipment, surgical site). If worn by patients, they prevent contamination of the patients' surroundings and environment. Standard surgical masks offer no protection to the practitioner undertaking laser procedures. If available, surgical masks or three ply cotton masks should be offered to patients undergoing non-facial laser procedures.

Filtering facepiece respirators (FFP), which are sometimes called disposable respirators protect from aerosol inhalation. FFP are tested in the direction of inspiration (from outside to inside). The tests take into account the efficiency of the filter and leakage to the face. FFP are subject to various regulatory standards around the world. FFP2 and FFP3 conform to EU standard EN149:2001. The FFP3 standard is often considered broadly equivalent to the US N99 standard and Chinese KN99 standard. The FFP2 standard is often considered broadly 
equivalent to the US N95 standard and Chinese KN95 standard.

Respirators are often more comfortable for the wearer when fitted with a valve exhalation feature, but this feature has the effect of elevating wearer safety over that of patients and others in the vicinity, and therefore is generally discouraged (Table 1$)^{11}$.

The World Health Organisation recommends that health care workers should wear a particulate respirator at least as protective as a N95/ FFP2, or equivalent, when performing aerosol-generating procedures on patients suspected or confirmed of being infected with COVID- $19^{12}$.

The BMLA also recommends that until proven otherwise, all patients should be considered suspected of being infected with COVID-19. All practitioners should wear N95 respirators as a minimum when undertaking any laser or IPL procedures. This should in addition be complemented by a reusable cleanable face shield. For all above-clavicle procedures, where risk of exposure to patient-generated respiratory aerosol is higher, where available, FFP3 respirators should be used instead (Chart 1).

Practitioners should be fit-tested for all respirators and should receive PPE training comprising proper hand hygiene practices, correct fit, donning and doffing to avoid crosscontamination(https://www.hse.gov.uk/respiratoryprotective-equipment/fit-testing-basics.htm).

Concerns about availability and costs of respirators should be taken into account. Unlike surgical masks which are single use (3-8 h maximum), FFP can be reusable or disposable. While the BMLA does not recommend extended use or reuse of disposable FFPs, when availability is an issue and, if unavoidable, it may be possible to extend the life of single use FFPs. The use of reusable, cleanable face shields may enhance the life of single-use FFPs. Thorough decontamination and safe storage of FFP are incumbent upon the user and are
Laser or IPL

procedure

Above clavicle

Below clavicle

FFP3 (N95 if FFP3 unavailable) with reusable, cleanable Face Shield and laser eye protection

N95 with reusable cleanable Face Shield and laser eye protection

Chart 1 Recommendations for facial personal protection equipment during laser/IPL procedures

beyond the scope of this guidance. Practices ranging from UV radiation (260-285 $\mathrm{nm}), 70{ }^{\circ} \mathrm{C}$ dry heat, $70 \%$ ethanol and vaporised hydrogen peroxide (VHP) can reduce SARSCoV-2 on N95 respirator with VHP treatment exhibiting the best combination of rapid inactivation of SARS-CoV-2 and preservation of N95 respirator integrity ${ }^{13,14}$.

\section{Ventilation}

As the SARS-CoV-2 spreads mainly through aerosol during AGP in enclosed spaces and as particle aerosol $(<10 \mu \mathrm{m})$ remains airborne for long durations in the laser treatment room and adjacent rooms, adequate ventilation is important to ensure appropriate air handling, containment and evacuation of contaminated air ${ }^{15}$.
Table 1 Differences between FFP2 and FFP3 filtering face piece respirators (source; https:// www.finder.com/uk/ffp2-vsffp3-face-masks] FFP2 FFP3

\begin{tabular}{|c|c|c|}
\hline & FFP2 & FFP3 \\
\hline \multicolumn{3}{|l|}{ Example } \\
\hline Conforms to & $\begin{array}{l}\text { EUROPE: EN 149:2001+ } \\
\text { A1:2009 }\end{array}$ & $\begin{array}{l}\text { EUROPE: EN 149:2001+ } \\
\text { A1:2009 }\end{array}$ \\
\hline $\begin{array}{l}\text { Minimum filter efficiency } \\
\text { requirement }\end{array}$ & $94 \%$ & $99 \%$ \\
\hline Filter efficiency tested using & Sodium chloride and paraffin oil & Sodium chloride and paraffin oil \\
\hline Filter efficiency test flow rate & $95 \mathrm{l} / \mathrm{min}$ & $951 / \mathrm{min}$ \\
\hline $\begin{array}{l}\text { Filter efficiency test particle } \\
\text { diameter }\end{array}$ & $0.3 \mu \mathrm{m}$ (approx.) & $0.3 \mu \mathrm{m}$ (approx.) \\
\hline $\begin{array}{l}\text { Maximum total inward leakage } \\
\text { requirement }\end{array}$ & $8 \%$ & $2 \%$ \\
\hline $\begin{array}{l}\text { Maximum permitted inhalation } \\
\text { resistance }\end{array}$ & $\begin{array}{l}0.7 \mathrm{mbar} \text { at } 301 / \mathrm{min} 2.4 \mathrm{mbar} \text { at } \\
95 \mathrm{l} / \mathrm{min}\end{array}$ & $\begin{array}{l}\text { 1.Ombar at } 30 \mathrm{I} / \mathrm{min} 3.0 \mathrm{mbar} \text { at } \\
951 / \mathrm{min}\end{array}$ \\
\hline $\begin{array}{l}\text { Maximum permitted exhalation } \\
\text { resistance }\end{array}$ & $3.0 \mathrm{mbar}$ at $160 \mathrm{I} / \mathrm{min}$ & $3.0 \mathrm{mbar}$ at $1601 / \mathrm{min}$ \\
\hline
\end{tabular}


Standard in-room air cleaners alone are not effective at protecting staff and preventing the spread of COVID-19. A HEPA (high-efficiency particulate air) filter uses mechanical filtration to remove airborne particles greater than or equal to $0.3 \mu \mathrm{m}$ in diameter at a minimum $99.97 \%$ efficiency and such filters are used in vacuum cleaners and in office buildings air management systems. Used alone, they are not adequate for medical practices.

ULPA (ultra-low particulate air) filters offer up to 99.9995\% efficiency on particles down to $0.12 \mu \mathrm{m}$. ULPA filters in air filtration systems and ductless fume hoods may help drawing in the airborne drops to capture and remove most of them from the airflow.

Where possible, air conditioning units should be serviced and set at exhaust to extract air from the room to outside the building rather than in air circulation modes. If required, air filters should be replaced in line with device manufacturers' recommendations. Negative-pressure rooms help control the spread of airborne-transmitted infections in health care facilities such as hospitals, but will not be readily available in high street clinics. If available, laser treatments should ideally be undertaken in negative pressure rooms ${ }^{11}$.

\section{Smoke evacuation systems}

Smoke evacuation systems are useful to reduce aerosol and plume generated during laser procedures but should be considered as an adjunct to hand hygiene, PPE and adequate ventilation. Laser smoke evacuation systems should have sub-micron filtration capability. Several smoke evacuation systems exist in the market but all offer certain common features such as ULPA filters and minimum flow rate of $25 \mathrm{cfm}$ (cubic feet per minute) with variable flow rate to accommodate various levels of smoke.

Some devices offer multistage filtration to ensure adequate removal of all contaminants. Charcoal filter comprises activated charcoal which absorbs gas and vapour. It helps in elimination of strong-smelling gases such as those released from laser hair removal. The optimised primary HEPA filter collects over $99.9 \%$ of all vaporised tissue and secondary ULPA filter removes solid and biological particles down to $0.01 \mu \mathrm{m}^{16,17}$.

It is important that smoke capture device (e.g. smoke evacuation pencil capture port, tubing) is positioned as close to the surgical site as possible to effectively collect all traces of surgical smoke. It has been shown that when the smoke extraction tip is moved only $2 \mathrm{~cm}$ from the treatment area, up to $50 \%$ of the particulate matter escaped into the local environment ${ }^{18}$, ${ }^{19}$. Used smoke evacuator filters, tubing and wands must be handled using standard precautions and disposed of as biohazardous waste ${ }^{20}$.

Smoke evacuation systems should be serviced as per manufacturer's recommendations to ensure that they function at maximum efficiency.

\section{Laser equipment and treatments}

Prior to resuming clinical services, practitioners much endeavour to switch on the lasers to check for any faults that may be addressed in good time. Additionally, as the lockdown has lasted for well over 10 weeks, it would be prudent for practitioners to spend some time for reorientation with laser protocols.

As SARS-CoV-2 can persist on inanimate surfaces such as metal, glass or plastic for up to 9 days, cleaning of laser equipment, display unit, hand pieces, guiding tips, patient goggles and practitioners' laser eyewear should be meticulously decontaminated after every treatment and as per manufacturer's recommendation $^{21}$. SARS-CoV-2 is efficiently inactivated by surface disinfection procedures with $62-71 \%$ ethanol, $0.5 \%$ hydrogen peroxide or $0.1 \%$ sodium hypochlorite within $1 \mathrm{~min}$. Practitioners must refer to manufacturerissued COSHH advice to ensure safety of use of these products on laser equipment ${ }^{21}$.

Although COVID-19 is not known to transmit through skin, pre-treatment skin cleansing should be meticulous as per local guidelines to reduce aerosolisation of the virus, if present on treatment site.

Additional measures can be employed to reduce the aerosol generation during laser treatments. To avoid the excessive dispersal of aerosol and plume during laser treatment, wherever possible, positive cold air flow used during laser treatments for the purpose of skin cooling should be substituted by alternative methods such as gels and disposable ice packs, which should in turn be appropriately disposed of as clinical waste and sapphire tips thoroughly cleansed post-procedure. It has been demonstrated that cold sapphire skin cooling with gel suppresses plume during laser hair removal ${ }^{22}$.

Similarly, use of hydrogel packs or cling film can reduce tissue splatter and aerosolisation during laser tattoo removal ${ }^{23}$.

Acknowledgements Mike Murphy-Laser Protection Adviser; Gen. Sec. of the UK Council on Surgical Plumes; Gen. Sec. of the Association of Laser Safety Professionals.

Dr. Godfrey Town Ph.D.- RPA2000 Accredited Laser Protection Adviser, Committee Member IEC TC76 WG4, TC61 WG30/MT16/ WG05/WG39 \& ANSI SSC-3, GCG Healthcare Ltd.

Jon Exley, Honorary Secretary-BMLA.

Vasant Oswal, Honorary Vice-President-BMLA.

Harry Moseley, Emeritus Professor and Past President-BMLA.

Reem Hana, Executive Committee Member-BMLA.

Tom Lister, Executive Committee Member-BMLA.

\section{Compliance with ethical standards}

Conflict of interest The authors declare that they have no conflict of interest.

Ethical approval Not applicable.

Declaration of interests Vishal Madan servers as honorary president of the British Medical Laser Association. 
Disclaimer Dr. Vishal Madan and the British Medical Laser Association (BMLA) make no guarantee or warranty as to the accuracy or completeness of any information published herein. Dr. Vishal Madan and the BMLA disclaim liability for any injury to persons or property or other damages of any nature whatsoever, whether special, indirect, consequential or compensatory, directly or indirectly resulting from the publication, use of, or reliance on this document. In issuing and making this document available, Dr. Vishal Madan and the BMLA are not undertaking to render professional or other services for or on behalf of any person or entity. Nor are Dr. Vishal Madan and the BMLA undertaking to perform any duty owed by any person or entity to someone else. Anyone using this document should rely on his or her own independent judgement or, as appropriate, seek the advice of a competent professional in determining the exercise of reasonable care in any given circumstances. Dr. Vishal Madan and the BMLA have no power, nor do they undertake, to police or enforce compliance with the contents of this document. Nor do Dr. Vishal Madan and the BMLA list, certify, test or inspect products, designs, or installations for compliance with this document. Any certification or statement of compliance with the requirements of this document shall not be attributable to Dr. Vishal Madan and the BMLA and is solely the responsibility of the certifier or maker of the statement.

\section{References}

1. https://www.bbc.co.uk/news/health-52473523 Accessed $24^{\text {th }}$ May 2020

2. Cleanliness, hygiene, infection \& cross infection control, Version: 3.1 Issued: 30.04.2020 GCG Healthcare Ltd accessed via https:// consultingroom.com/relaunch/index.php Accessed $24^{\text {th }}$ May 2020

3. https://www.nhs.uk/conditions/SARS-CoV-2-covid-19/check-ifyou-have-SARS-CoV-2-symptoms/\#symptoms Accessed $24^{\text {th }}$ May 2020

4. Sima Asadi, Nicole Bouvier, Anthony S Wexler, William D Ristenpart. The SARS-CoV-2 pandemic and aerosols: does COVID-19 transmit via expiratory particles Editorial. Aerosol Sci Technol.2020, 3;0:1-4

5. Leung WWF, Sun Q (2020) Electrostatic charged nanofiber filter for filteringairborne novel coronavirus (COVID-19) and nano-aerosols. Separation and Purification Technology. https://doi.org/10. 1016/j.seppur.2020.116886

6. Chuang GS, Farinelli W, Christiani DC, Herrick RF, Lee NCY, Avram MM (2016 Dec 1) Gaseous and particulate content of laser hair removal plume. JAMA Dermatol 152:1320-1326

7. Garden JM, O'Banion MK, Bakus AD, Olson C (2002) Viral disease transmitted by laser-generated plume (aerosol). Arch Dermatol 138:1303-1307

8. Murphy MJ (2018) High speed aggregates are ejected from tattoos during Q-switched Nd:YAG laser treatments. Lasers Surg Med. https://doi.org/10.1002/lsm.22817 Online ahead of print

9. Wang W, Xu Y, Gao R, Lu R, Han K, Wu G et al (2020) Detection of SARS-CoV-2 in different types of clinical specimens. JAMA. 323:1843-1844

10. https://www.youtube.com/watch?v=-GncQ_ed-9w Accessed $24^{\text {th }}$ May 2020
11. Dover JS, Moran ML, Figueroa JF, Furnas H, Vyas JM, Wiviott LD, Karchmer AW (2020) A path to resume aesthetic care: executive summary of project AesCert guidance supplement-practical considerations for aesthetic medicine professionals supporting clinic preparedness in response to the SARS-CoV-2 outbreak. Facial Plast Surg Aesthet Med 22:125-151

12. https://www.who.int/docs/default-source/documents/advice-onthe-use-of-masks-2019-ncov.pdf Accessed 24 ${ }^{\text {th }}$ May 2020

13. https://www.medrxiv.org/content/10.1101/2020.04.11. 20062018v2.full.pdf Accessed 24 $4^{\text {th }}$ May 2020

14. https://www.cdc.gov/niosh/topics/hcwcontrols/ recommendedguidanceextuse.html Accessed $24^{\text {th }}$ May 2020

15. Air cleaning technologies. Ontario Health Technology Assessment Series 2005; Vol. 5, No. 17

16. Fencl JL (2017) Guideline implementation: surgical smoke safety. Aorn J 105(5):488-497

17. Walker B High efficiency filtration removes hazards from laser surgery. Natnews 27(6):10-12

18. Katoch S, Mysore V (2019) Surgical smoke in dermatology: its hazards and management. J Cutan Aesthet Surg 12(1):1-7

19. Ziegler BL, Thomas CA, Meier T, Müller R, Fliedner TM, Weber L (1998) Generation of infectious retrovirus aerosol though medical laser irradiation. Lasers Surg Med 22:37-41

20. Ball K (2004) Controlling surgical smoke: a team approach. Phoenix (AZ), IC Medical Inc

21. Kampf $\mathrm{G}$ et al (2020) Persistence of coronaviruses on inanimate surfaces and their inactivation with biocidal agents. J Hosp Infect 104:246-251

22. Ross EV, Chuang GS, Ortiz AE, Davenport SA (2018) Airborne particulate concentration during laser hair removal: a comparison between cold sapphire with aqueous gel and cryogen skin cooling. Lasers Surg Med 50:280-283

23. Govindan K, Thomas K, Baker L, Kenealy J (2006) Use of hydrogel pad in laser treatment of tattoos. J Plast Reconstr Aesthet Surg $59: 887-888$

Summary Aerosols can carry viruses - these can be generated by coughs, sneezes and talking.

Laser/IPL procedures may also generate aerosols.

All patients should wear surgical masks (or similar) when in the clinic.

All laser/IPL operators should wear FFP2/N95 or FFP3/N99 respirators during treatments, preferably with face shields.

High efficiency smoke evacuation systems should be used to reduce plume generated during laser procedures.

All equipment and work surfaces should be decontaminated between procedures.

Good air ventilation should be used to clean the air between patients.

Publisher's note Springer Nature remains neutral with regard to jurisdictional claims in published maps and institutional affiliations. 